NASA Technical Memorandum 88965

\title{
Computational Composite Mechanics for Aerospace Propulsion Structures
}

\author{
(NASA-TM-88965) CCAFETAIICNAI CCNECSITE N87-1E614 \\ DECHANICS FCB AEECSEACE FFCECISICA \\ STRUCTURES (NASA) $19 \mathrm{~F}$ CSCL $11 D$ \\ Unclas \\ G3/24 43644
}

Christos C. Chamis

Lewis Research Center

Cleveland, Ohio

Prepared for the

3rd Space Systems Technology Conference

sponsored by the American Institute of Aeronautics and Astronautics

San Diego, California, June 9-12, 1986 
COMPUTATIONAL COMPOSITE MECHANICS FOR AEROSPACE PROPULSION STRUCTURES

\author{
Christos C. Chamis* \\ National Aeronatics and Space Administration \\ Lewis Research Center \\ Cleveland, Ohio 44135
}

\begin{abstract}
SUMMARY
Specialty methods are presented for the computational simulation of specific composite behavior. These methods encompass all aspects of composite mechanics, impact, progressive fracture, and component specific simulation. Some of these methods are structured to computationally simulate, in parallel, the composite behavior and history from the initial fabrication through several missions and even to fracture. Select methods and typical results obtained from such simulations are described in detail in order to demonstrate the effectiveness of computationally simulating (1) complex composite structural behavior in general and (2) specific aerospace propulsion structural components in particular.
\end{abstract}

\title{
INTRODUCTION
}

Fiber composites have distinct advantages over conventional materials which make composites highly desirable candidates for application in aerospace propulsion structures. Some of these advantages include the well known high strength/density and modulus/density ratios. Other advantages include high fatigue resistance, resistance to defects, high damping, and "zero" thermal expansion. Practically all of these advantages derive from the inherent anisotropic and heterogeneous structure of fiber composites. This inherent structure which provides composites with their distinct advantages also substantially increases the complexity required to formally describe their structural behavior.

Over the past 15 yr NASA Lewis Research Center has been developing specialty methods for the analysis/design of composite structures. By virtue of their complexity, these methods are computationally intensive and, by necessity, are in the form of independent computer codes or are embedded as modules in more general structural analysis codes (refs. 1 to 3 ). Collectively, the development of these various specialty methods constitute a new discipline identified as computational composite mechanics. These methods have been structured to simulate the history of composite thermal, structural and material degradation behavior beginning with the fabrication processes through several flight missions. The objective of this paper is to briefly describe these methods and to fllustrate their application to general composite behavior as well as to select aerospace propulsion structures.

Briefly, these methods encompass all aspects of composite mechanics, impact, progressive fracture, and component specific composite structural analysis. The select applications included in the paper were chosen to illustrate

* Senior Research Engineer - Aerospace Structures/Composites, Structures Division; AIAA Associate Fellow. 
(1) the computational simulation of composite structural behavior of importance to aerospace propulsion structures and (2) the structural behavior of specific composite structural components in aerospace propulsion service environments. The applications are presented with a brief description of: (1) the importance of the behavior to be simulated, (2) the simulation procedure, and (3) typical results obtained and their respective significance.

\section{Interply Layer Progressive Degradation Effects on Composite Structural Response}

Fiber reinforced composites are optimally utilized when they are required to resist and/or transfer only in-plane loads. Fibers are oriented in different layers (plies) to resist these in-plane loads either in tension or compression. The different plies are held together by the interply (interlaminar) layers (matrix) which provide the composite with the structural integrity required to resist the in-plane loads. Any degradation of the interply layer will, therefore, affect the composite structural integrity. As a result, interply layer degradation effects on fiber composite structural integrity is receiving considerable research attention. Interply degradation is generally either in the form of delaminations or progressive weakening of the interply layer. In either case, the angleplied laminate will most likely behave like a stack of individual layers (beams) instead of a composite. Compared to the undelaminated composite, individual delaminated layer behavior dramatically degrades out-of-plane structural response such as flexural deflections (bending), buckling, vibration, and impact. For example: (1) the flexural deflection increases as the square of the number of delaminated layers; (2) the flexural stress increases linearly with the number of delaminated layers; (3) the buckling load decreases as the square of the number of delaminated layers; and (4) the frequency decreases linearly with the number of delaminated layers.

Computational simulation (ref. 4) was used to determine and assess the effects of interply layer progressive weaking (degradation) on various structural responses of composite beams. The structural responses of interest include: (1) bending, (2) buckling, (3) free vibrations, (4) periodic excitation, and (5) impact. The computational simulation consisted of composite mechanics in conjunction with finite element analysis. The interply layer degradation effects on the various structural responses were determined and assessed as a function of the interply layer modulus, varying from $1 \mathrm{~m} p s i$ down to $1 \mathrm{ksi}$, and even lower for some limiting cases. The results obtained show that interply layer degradation generally has negligible effect on composite structural integrity unless the interply layer modulus degrades to about $10 \mathrm{ks} i$ or less.

Computational simulation results obtained for the interply (adhesive or matrix) layer degradation effects on the forced vibration response of a simply supported beam are presented in figure 1. The third mode vibration amplitude is shown without damping and with damping as a function of interply layer modulus and shear stress. These results illustrate that the interply layer degra dation effects on complex composite structural response can be quantified by suitable computational simulation.

\section{Dynamic Structural Response of Unnotched and Notched Fiber Composites}

Unnotched and notched flexural specimen testing continues to be popular in the composites community for characterizing and/or qualifying fiber compos. 
ites for structural applications. These experimental techniques are popular because of: (1) simplicity, (2) adaptability to adverse environments, (3) availability of simple equations for data reduction, and (4) availability of written ASTM standard testing procedures. In addition, flexural specimen testing forces the material to respond like a structure by simultaneously subjecting it to tensile, compressive, and shear stresses. Furthermore, notched flexural specimen (Charpy impact test specimen) testing enables easy determination of fracture toughness and impact resistance.

Fracture, in general (be it static, quasistatic, or dynamic) is a dynamic event and, as such, is a very complex process. The fracture progression in a flexural specimen is controlled by the local dynamic stress field which is also complex. The local dynamic stress field is characterized by stress waves which are normal, shear, flexural, and surface waves. Each of these dynamic stresses can initiate failure (or a defect) at a point and/or propagate this defect to fracture. For a complete understanding of these phenomena, a detailed description of the local dynamic stress field is a prerequisite.

The detailed description/quantification of the local dynamic stress field can be determined using computational simulation. The computational simulation (ref. 5) consists of composite mechanics, and finite element transient analysis. The procedure is demonstrated by applying it to the impact response (displacements, velocities, stresses, and wave propagations) in Charpy-type composite beams.

For the geometry (fig. 2) and type of materials studied, the static analysis results gave close conservative estimates for the dynamic stresses. other interesting results from the study are: (1) the impact-induced effects propagate in S-GLASS/EPOXY specimens sooner than KEVLAR/EPOXY or T-300/EPOXY specimens, (2) the vibration mode shapes are coupled, exhibiting flexural, stretching and shearing motions, (3) the specimen responds for the impact load duration only, (4) severe stress magnitudes are developed at the notch tip region leading to fracture initiated by combined transverse normal and shear stresses and followed by fiber breakage caused by large flexural tensile stresses in this region. Typical results are shown in figure 3 for the displacement propagation in beams made from three different composite materials. These results demonstrate the effectiveness of computational simulation to determine the dynamic response of composite structural components.

\section{Interlaminar Fracture Toughness in Fiber Composites}

Interlaminar delamination of composites is a type of fracture mode which needs to be carefully examined and properly accounted for in the design of composite structures. Regions prone to delaminations include free edges, locations of stress concentration, joints, damaged areas, and defects resulting from the fabrication process.

One way to properly account for interlaminar delamination in a design is to determine interlaminar fracture toughness parameters and then evaluate stress states which are likely to induce interlaminar fracture. Several test methods to determine fracture toughness have been proposed and are currently being used. However, these test methods may not discriminate the participating and respective magnitudes of the different fracture modes. An alternate approach is a suitable computational simulation. 
Recent exploratory research at NASA Lewis (ref. 6) resulted in the development of a computational method (procedure) for simulating interlaminar fracture toughness in fiber composites. This computational procedure involves three-dimensional finite element analysis, including modeling of interply layers, in conjunction with the strain energy release rate concept and composite micromechanics. The procedure is suitable for determining global and local interlaminar fracture toughness parameters as well as critical values of these parameters (fig. 4). Predicted results using this procedure are in good agreement with limited available data from end-notch flexure and/or mixed-mode fracture test specimens (fig. 5).

During the development of the procedure for the computational simulation of fracture toughness it was observed that (1) fracture toughness is a structural parameter and not a material characteristic as is normally considered, and (2) critical fracture toughness parameters for rapid defect growth in a structural component can be determined by computational simulation. Both of these demonstrate, in part, that computational simulation is not only applicable to quantify complex structural behavior but it is also applicable to identify new phenomena and/or relationships.

\section{Progressive Fracture in Fiber Composites}

Determination of progressive fracture in composite laminates is fundamental and generic to developing the methodology for quantifying composite structures durability and reliability. Research activities on progressive composite fracture at NASA Lewis during the last 10 yr have culminated in the development of the CODSTRAN computer code (refs. 7 to 9). CODSTRAN (Composite Durability Structural Analysis) has been specifically developed for the computational simulation of progressive fracture in fiber composites.

CODSIRAN is a modular program that does quantitative calculations to predict defect growth and progressive fracture in composite structural components. Capabilities of CODSTRAN include determining the durability of composites with and without defects, determining structural responses due to mechanical and thermal loads, accurate prediction of stress states near defects (stress concentrations), and prediction of ply and laminate level failure and fracture. The modules comprising CODSTRAN are: (1) the executive module, containing communication links to all other modules; (2) the $1 / 0$ module; (3) the Analysis module; (4) the Composite Mechanics Module; and (5) the Fracture Mechanics module.

The Analysis module is the general purpose finite element computer code NASIRAN and is used to calculate both near-field and far-field stresses in a finite element model of the structural component or specimen. The composite Mechanics (ref. 3) module generates laminate properties from constituent properties (composite micromechanics) and uses intraply failure and interlaminar delamination criteria to check ply and interply fallure, respectively. The Fracture Mechanics module is able to account for both ply level fracture and laminate fracture. The modified distortion energy principle and/or a general quadratic surface fit are used to indicate combined ply level fracture. Laminate level fallure is assumed to occur when all the plies in the laminate have falled in all the fallure modes.

To computationally simulate progressive fracture, COOSTRAN uses an interative procedure whereby a load is applied incrementally to the finite element 
model of the structure being modeled. The response of the structure to the load can be no damage, damage, or destruction of an element(s) (local fracture). Based upon this response, the load increment is updated as follows: (1) if no damage is predicted, the load is updated by some predetermined load increment; (2) if elements are damaged or destroyed (defect growth or local fracture), the same load is reapplied with reduced material properties assigned to the damaged elements. Destroyed elements are purged from the finite element mesh, effectively defining progressive fracture. This load is maintained until equilibrium in the structure is achieved. Equilibrium, is defined as the point where the structure, with its updated geometry and modified material properties, can sustain the applied load without the occurrence of further damage. This iterative procedure is continued through load increments until global fracture of the structure occurs. Typical computationally simulated progressive fracture results are shown in figure 6 . These results, perhaps more than any other, demonstrate the effectiveness of composite mechanical computational simulation.

\section{Fiber Composite Sandwich Thermostructural Behavior}

The use of fiber composites in space applications is increasing in a variety of structural configurations. Sandwich structural configurations provide an effective application of fiber composites. The faces of the sandwich resist loads by membrane action which is the most structural-efficient use of fiber composite thin laminates. In addition, composite sandwiches can be tailored to meet very close thermal distortion tolerances such as those required for communication satellite antennas.

Designs to meet close thermal distortion tolerances are determined by detalled heat transfer, thermal, and structural analyses. These analyses require respective thermal and mechanical properties of the composite sandwich as well as temperature and moisture effects on these properties. Thermal properties include heat capacity, thermal conductivities and thermal expansion coefficients in the plane and through the thickness of the sandwich. The corresponding mechanical properties include normal and shear moduli and Poisson's ratios. Thermomechanical and corresponding thermostructural properties of sandwiches can in principle be measured. This is practical only for one or at most a few sandwich configurations, limited temperature/moisture conditions and generally for selected properties. The alternative is to computationally simulate the thermomechanical behavior of composite sandwiches so that all the properties required for thermal and mechanical/structural analyses can be predicted including hygrothermal effects. Though this is seemingly "straightforward," it is not available in the literature to the authors 'knowledge. Recent research at NASA Lewis focused on developing computational methods for simulating the thermomechanical behavior of composite sandwiches (ref. 10 ). These methods use analyses with several levels of progressive sophistication/ simplification in conjunction with composite hygrothermomechanical theory.

The several levels of sophistication include: (1) three-dimensional finite element modeling of the honeycomb, the adhesive and the composite faces (fig. 7); (2) three-dimensional finite element modeling of the honeycomb assuming an equivalent homogeneous medium, the adhesive and the composite faces (fig. 8); (3) laminate theory simulation where the honeycomb (metal or composite) is assumed to be of plies with equivalent properties (fig. 8 without the finite element mesh); (4) derivation of approximate, simplified equations for simulating the honeycomb thermal and mechanical properties with an equivalent 
homogeneous medium; and (5) hygrothermal effects from cryogenic to $250^{\circ} \mathrm{F}$ with and without moisture.

Typical results obtained from the several levels of sophistication/ simplification are summarized in table I. These results illustrate yet another application of computational simulation: an effective means to aid the development of approximate simple and explicit methods for predicting complex thermostructural behavior.

\section{High Temperature Metal Matrix Composite (HT-MMC) Structures}

The use of advanced high temperature composite materials in aerospace propulsion systsems is becoming more attractive. The potential benefit is derived from the ability of these materials to allow higher operating temperatures resulting in improved engine performance/efficiency and, at the same time, to enhance or at least maintain component durability. For example, qualitative investigations have identified the tungsten-fiber-reinforced superalloys (TFRS) as a potential first-generation composite aircraft turbine and Space Shuttle Main Engine (SSME) turbopump blade/vane material by virtue of the excellent combination of complementary properties provided by this family of advanced high-temperature composites. In order to adequately investigate the feasibility of using TFRS for turbine engine and SSME components, computational simulation methods are needed which account for the complex physics associated with these applications including: nonlinear (stress-temperature-time dependent) and anisotropic constituent (fiber/matrix) material behavior, micro- and macroheterogenity, and $f i b e r / m a t r i x$ interdiffusion.

Research activities at NASA Lewis over the past $5 \mathrm{yr}$ lead to the development of Nonlinear COBSTRAN (Composite Blade Structural Analysis) for the com. putational simulation of HT.MMC blades (refs. 11 to 13). Nonlinear COBSTRAN embodies an upward integration/downward decomposition strategy to predict thermomechanical structural response. This strategy comprises: (1) thermomechanical diffusion model, (2) nonlinear material constitutive models, (3) composite mechanics, and (4) global finite element structural analysis (fig. 9). Nonlinear COBSIRAN has been used to trace the behavior of HT-MMC components from fabrication through one or more missions. Results demonstrate that nonlinear COBSIRAN is computationally effective. It provides a direct means for predicting the complex behavior at all levels of the composite simulation; that is, from the constituent materials, through the several levels of composite mechanics, to the local/global structural response of complex HT-MMC structural components sub- ject to representative engine mission loads (fig. 10).

Typical results obtained for the blade and mission shown in figure 10 are presented in figure 11 . The important observation is that it would be practically impossible to determine this type of detailed behavior without computational simulation.

\section{CONCLUSIONS}

Over the past 15 yr NASA Lewis Research Center has been developing spec. ialty methods for the analysis/design of composite structures. By virtue of their complexity, these methods are computational intensive and, by necessity, are in the form of independent computer codes or are embedded as modules in 
more general structural analysis codes. Collectively, the development of these various specialty methods constitute a new discipline identified as computational composite mechanics. These methods encompass all aspects of composite mechanics, impact, progressive fracture, and component specific composite structural analysis. The application of computational simulation to select examples are briefly described in terms of (1) the importance of the behavior simulated, (2) the simulation procedure, (3) typical results obtained, and (4) interpretation and significance of these results. Collectively, these examples demonstrate the effectiveness, and perhaps the only coupled/integrated means of computational simulation for determining the complex structural response of composite structures in aerospace propulsion service environments.

\section{REFERENCES}

1. Chamis, C.C., "Integrated Analys is of Engine Structures," NASA TM-82713, 1981.

2. Chamis, C.C. and Sinclair, J.H., "INHYD: Computer Code for Intraply Hybrid Composite Design," NASA TP-2239, 1983.

3. Murthy, P.L.N. and Chamis, C.C., "ICAN - Integrated Composites Analyzer," AIAA Paper 84-0974, May 1984.

4. Chamis, C.C. and Williams, G.C., "Interply Layer Degradation Effects on Composite Response," Journal of Aircraft, Vol. 22, No. 7, July 1985, pp. $573-580$.

5. Murthy, P.L.N. and Chamis, C.C., "Dynamic Stress Analys is of Smooth and Notched Fiber Composite Flexural Specimens," Composite Materials: Testing and Design, J.M. Whitney, ed., ASTM STP-893, ASTM, Phíladelphia, PA, 1986, pp. 368-391.

6. Murthy, P.L.N. and Chamis, C.C., "Interlaminar Fracture Toughness: Three-Dimensional Finite-Element Modeling for End-Notch and Mixed-Mode Flexure," NASA TM-87138, 1985.

7. Chamis, C.C. and Smith, G.T., "CODSTRAN: Composite Durability Structural Analys is," NASA TM-79070, 1978.

8. Irvine, T.B. and Ginty, C.A., "Progressive Fracture of Fiber Composites," Journal of Composite Materials, Vol. 20, Mar. 1986, pp. 166-184.

9. Irvine, T.B. and Ginty, C.A., "fracture Modes in Notched Angleplied Composite Laminates," NASA TM-83802, 1984.

10. Chamis, C.C., Aiello, R.A., and Murthy, P.L.N., "Fiber Composite Sandwich Thermostructural Behavior: Computational Simulation," AIAA 27th Structures, Structural Dynamics and Materials Conference, AIAA, 1986, pp. $370-381$.

11. Hopkins, D.A., "Nonlinear Analysis of High Temperature Multilayered Fiber Composite Structures," NASA TM-83754, 1984.

12. Hopkins, D.A. and Chamis, C.C., "A Unique Set of Micromechanics Equations for High Temperature Metal Matrix Composites," NASA TM-87154, 1985. 
13. Chamis, C.C. and Hopkins, D.A., "Thermoviscoplastic Nonlinear Constitutive Relationships for Structural Analysis of High Temperature Metal Matrix Composites," NASA TM-87291, 1985. 
TABLE I. - SUMMARY OF RESULTS FROM THREE DIFFERENT

SIMULATION LEVELS OF PROGRESSIVE SIMPLIFICATION

\begin{tabular}{|c|c|c|c|c|c|c|}
\hline \multicolumn{4}{|c|}{ Property description } & \multicolumn{2}{|c|}{$\begin{array}{l}\text { Three-dimensional } \\
\text { finite element }\end{array}$} & \multirow[t]{2}{*}{$\begin{array}{l}\text { Laminate } \\
\text { theory }\end{array}$} \\
\hline Property & Units & Symbol & Direct. & $\begin{array}{l}\text { Detalled } \\
\text { model }\end{array}$ & $\begin{array}{l}\text { Homogen. } \\
\text { core model }\end{array}$ & \\
\hline $\begin{array}{l}\text { Normal } \\
\text { modulus }\end{array}$ & $\begin{array}{l}\text { mpsi } \\
\text { mpsi } \\
\text { mpsi }\end{array}$ & $E$ & $\begin{array}{l}x x \\
y y \\
z z\end{array}$ & $\begin{array}{c}1.0 \\
1.0 \\
.09\end{array}$ & $\begin{array}{c}1.0 \\
1.0 \\
.09\end{array}$ & $\begin{array}{l}1.0 \\
1.0 \\
.09\end{array}$ \\
\hline \multirow[t]{3}{*}{$\begin{array}{l}\text { Shear } \\
\text { modulus }\end{array}$} & $\operatorname{mps} 1$ & G & $\begin{array}{l}x y \\
y x\end{array}$ & .39 & .38 & .38 \\
\hline & $m p s i$ & G & $\begin{array}{l}y z \\
z y\end{array}$ & .071 & .071 & .071 \\
\hline & mpst & G & $\begin{array}{l}z x \\
x z\end{array}$ & .075 & .074 & .076 \\
\hline \multirow[t]{3}{*}{$\begin{array}{l}\text { Poisson's } \\
\text { ratio }\end{array}$} & & $v$ & $\begin{array}{l}x y \\
y x\end{array}$ & $\begin{array}{l}.396 \\
.348\end{array}$ & $\begin{array}{l}.315 \\
.315\end{array}$ & $\begin{array}{l}.374 \\
.374\end{array}$ \\
\hline & & $v$ & $\begin{array}{l}y z \\
z y\end{array}$ & $\begin{array}{l}.121 \\
.073\end{array}$ & $\begin{array}{l}.043 \\
.005\end{array}$ & $-\cdots-$ \\
\hline & & $v$ & $\begin{array}{l}z x \\
x z\end{array}$ & $\begin{array}{l}.030 \\
.118\end{array}$ & $\begin{array}{l}.004 \\
.045\end{array}$ & $\begin{array}{l}----- \\
-----\end{array}$ \\
\hline $\begin{array}{l}\text { Therma } 1 \\
\text { exp. coeff. }\end{array}$ & uin. $/$ in. $/^{\circ} \mathrm{F}$ & $\alpha$ & $\begin{array}{l}x x \\
y y \\
z z\end{array}$ & $\begin{array}{l}1.31 \\
1.38 \\
-\end{array}$ & $\begin{array}{l}1.21 \\
1.21 \\
14.6\end{array}$ & $\begin{array}{c}1.21 \\
1.21 \\
13.6\end{array}$ \\
\hline Thermal heat & $\begin{array}{l}\text { Btu-in. } / \\
\mathrm{hr} / \text { in. } 2 /^{\circ} \mathrm{F}\end{array}$ & K & $\begin{array}{l}x x \\
y y \\
z z\end{array}$ & $\begin{array}{l}.191 \\
.181 \\
.043\end{array}$ & $\begin{array}{l}.191 \\
.183 \\
.043\end{array}$ & $\begin{array}{l}.190 \\
.182 \\
.041\end{array}$ \\
\hline
\end{tabular}




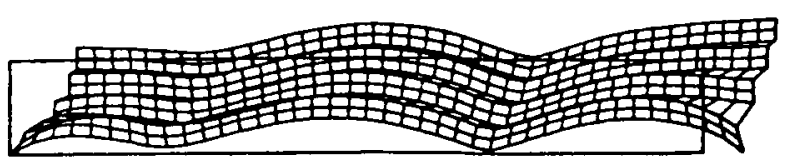

(50X; UNIFORM DAMPING = 0.01; E - $10000 \mathrm{psi}$ )
INTERPLY

MODULUS,

psi

- 500000

$\triangle \quad 100000$

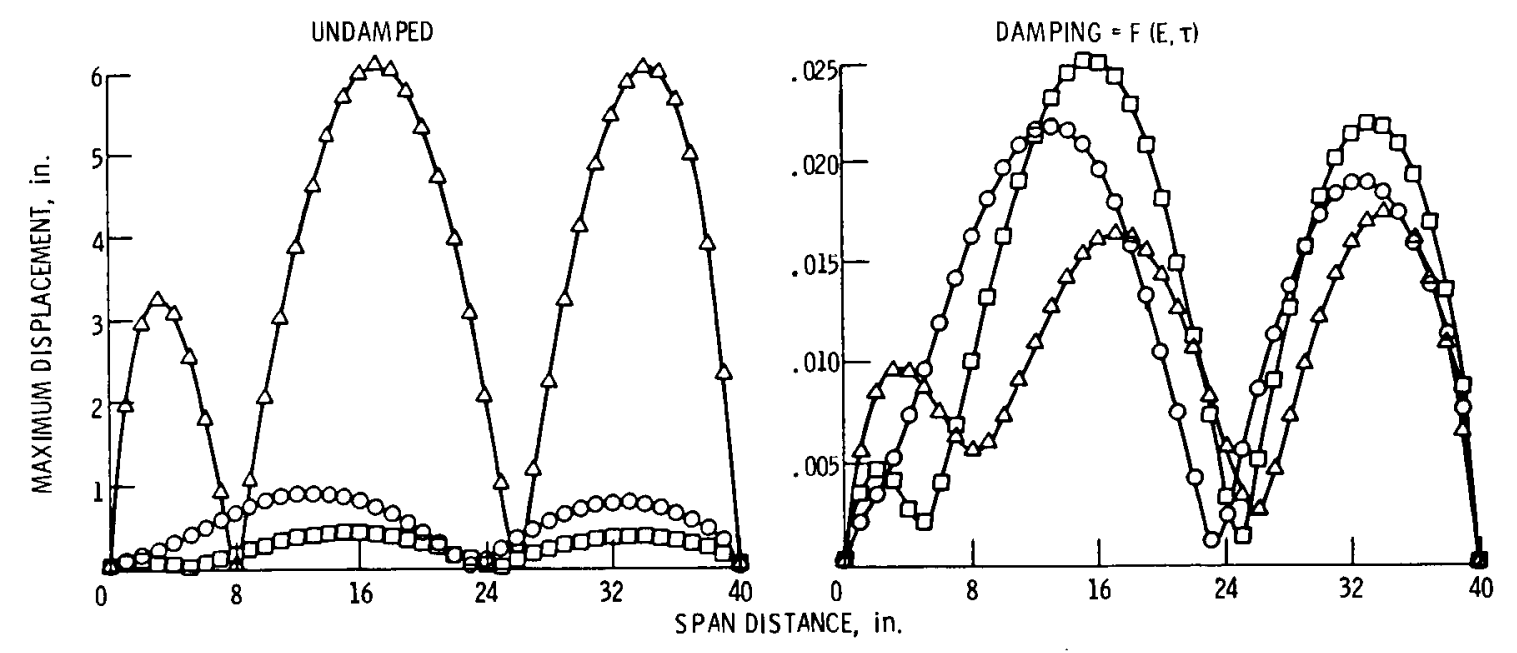

FIGURE 1. - INTERPLY LAYER DEGRADATION EFFECTS ON FORCED VIBRATION RES PONSE (3rd MODE).

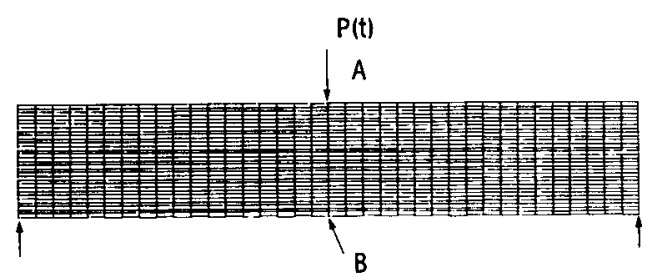

UNOTCHED SPECIMEN

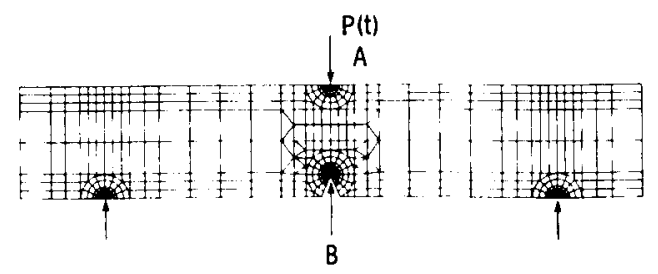

NOTCHED SPECIMEN

FIGURE 2. - FINITE ELEMENT MODELS FOR IMPACT SIMULATION. 


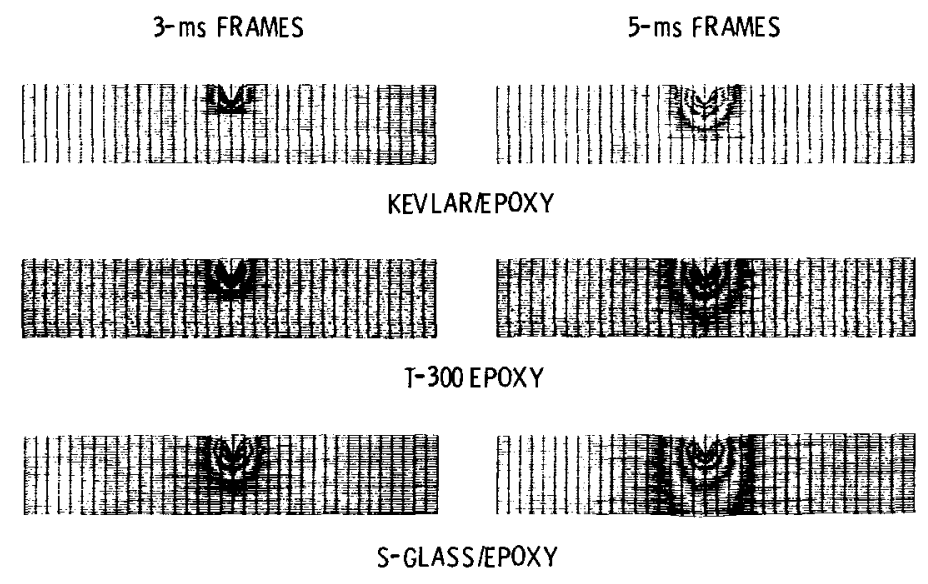

FIGURE 3. - DISPLACEMENT PROPAGATION DUE TO IMPACT.

- DETERMINE REQUISITE PROPERTIES AT DESIRED CONDITIONS USING COMPOSITE MICROMECHANICS

- RUN 3-D FINITE ELEMENT ANALYSIS ON ENF (MMF) FOR AN ARBITRARY LOAD

- SCALE LOAD TO MATCH INTERLAMINAR SHEAR STRESS AT ELEMENT NEXT TO CRACK-TIP

- WITH SCALED LOAD EXTEND CRACK AND PLOT STRAIN ENERGY RELEASE RATE VERSUS CRACK LENGTH

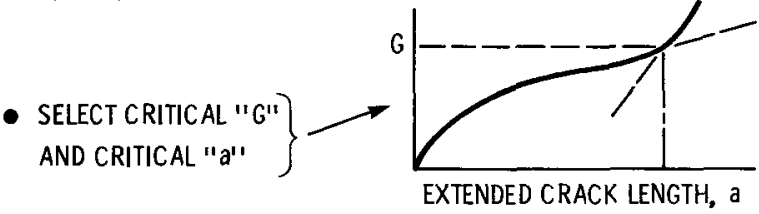

- METHOD HAS VERSATILITY/GENERALITY

FIGURE 4. - GENERAL PROCEDURE FOR SIMULATING INTERLAMINAR FRACTURE TOUGHNESS (END-NOTCH OF MIXED-MODE FRACTURE). 


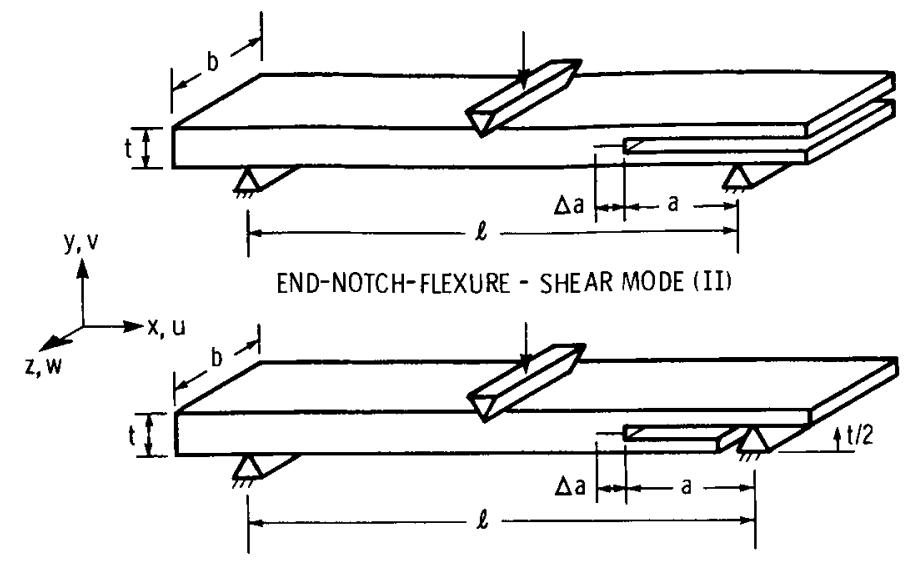

MIXED-MODE-FLEXURE - MIXED MODE (I AND II)

FIGURE 5. - SCHEMATICS OF TEST SPECIMENS FOR INTERLAMINAR FRACTURE TOUGHNESS.

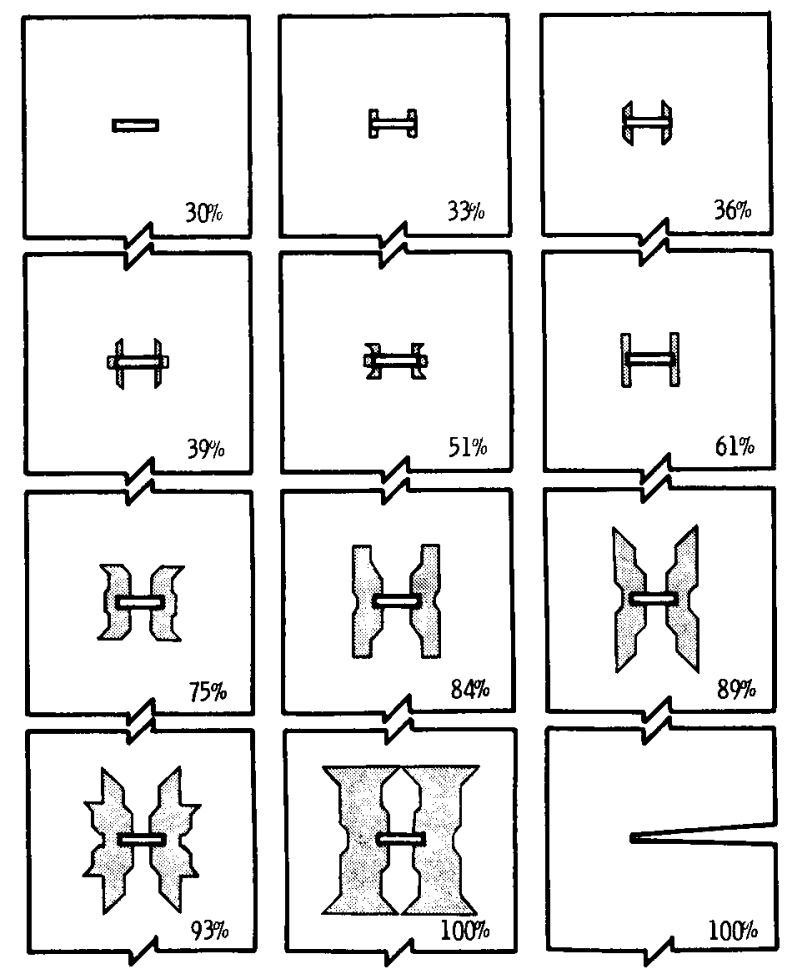

FIGURE 6. - COMPUTATIONALLY SIMULATED PROGRESSIVE FRACTURE AT VARIOUS PERCENTAGES OF THE FRACTURE LOAD (15 $402 \mathrm{lb}$; GrE $\left.[0 /+30 / 0 /-30 / 0]_{2 S}\right)$. 


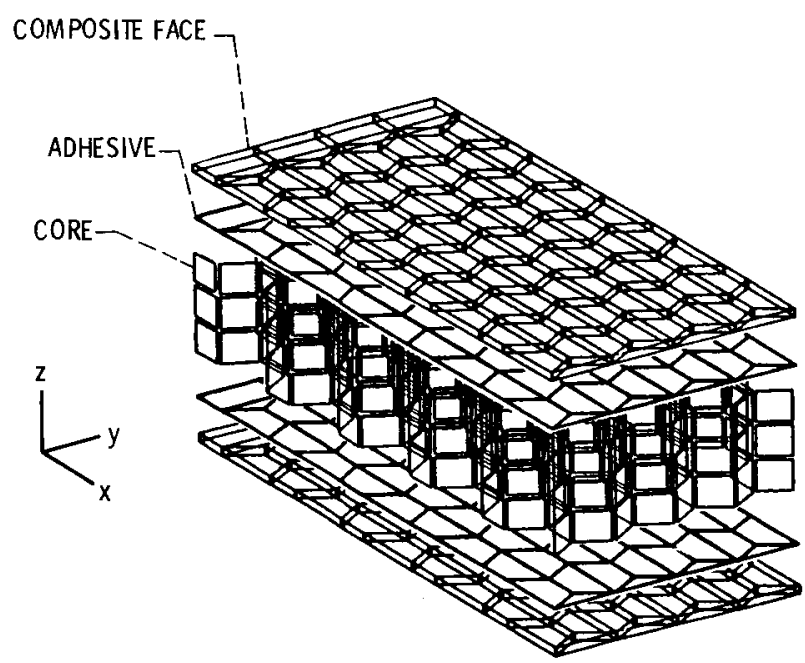

FIGURE 7. - 3-D DETAILED FINITE ELEMENT MODEL OF COMPOSITE SANDWHICH WITH HONEYCOMB CORE.

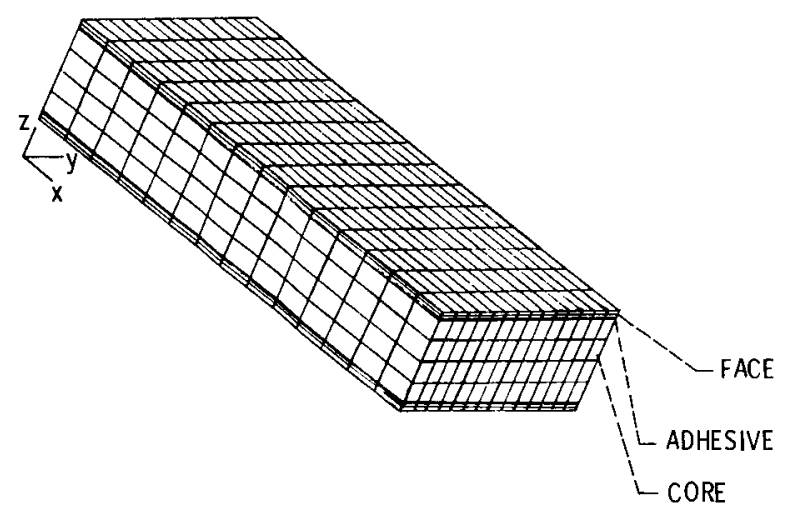

FIGURE 8. - 3-D FINITE ELEMENT MODEL OF COMPOSITE SANDWICH WITH EOUIV ALENT HOMOGENEOUS-MEDIUM CORE. 


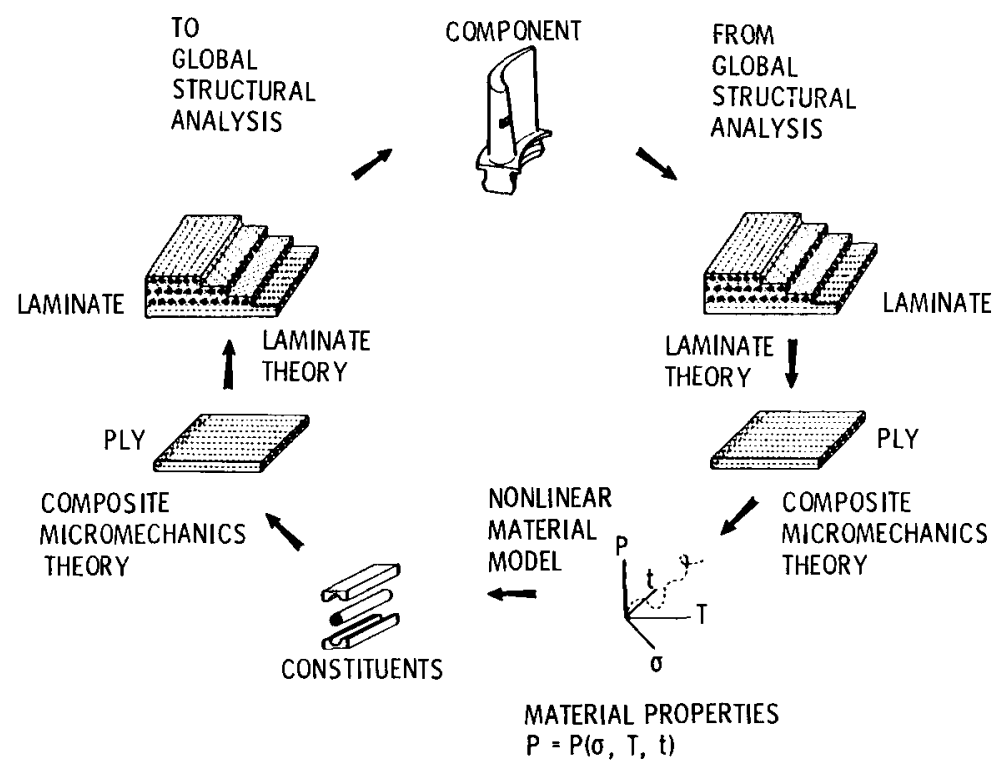

FIGURE 9. - NONLINEAR COBSTRAIN SIMULATION OF HIGH IEMPERATURE METAL MATRIX COMPOSITES. 


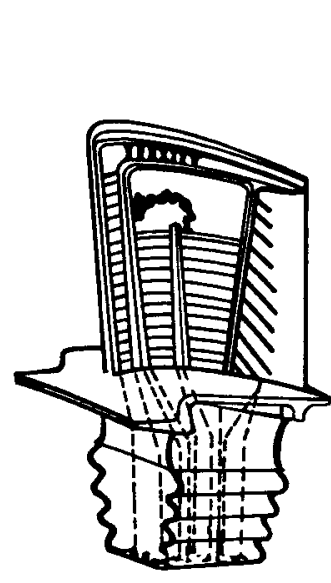

TURBINE BLADE
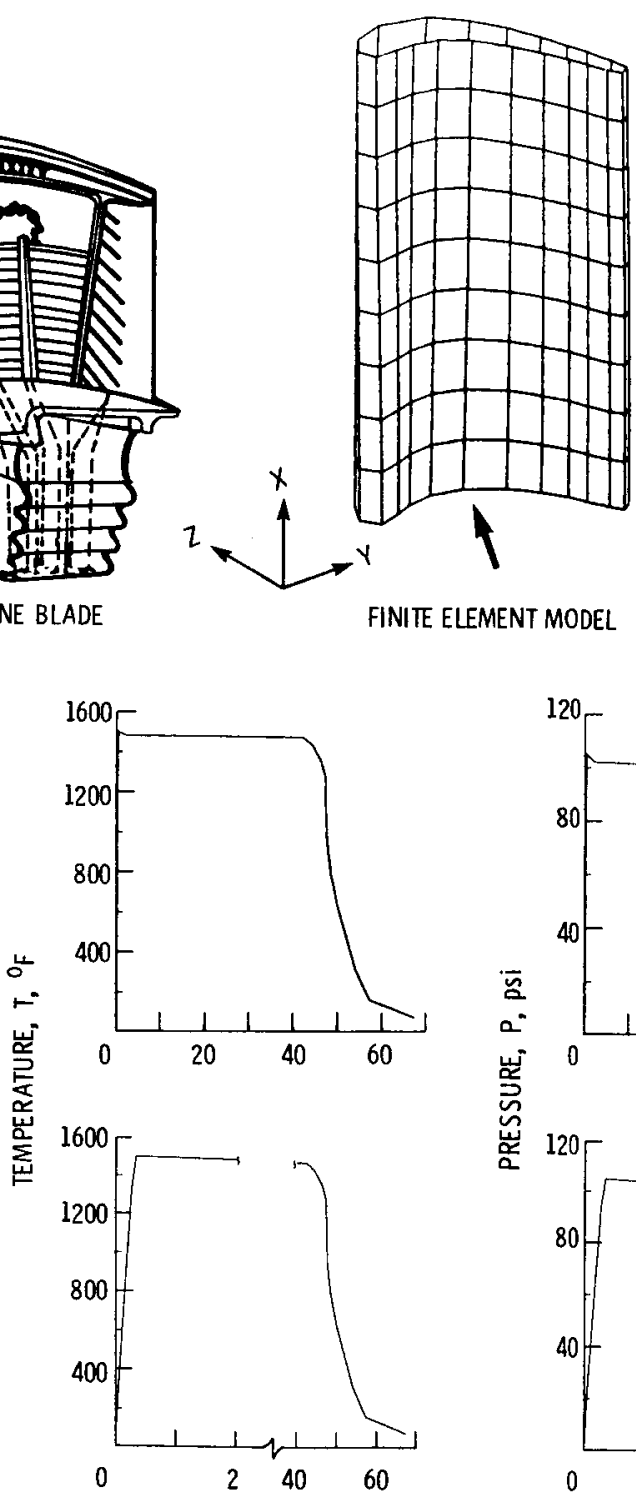
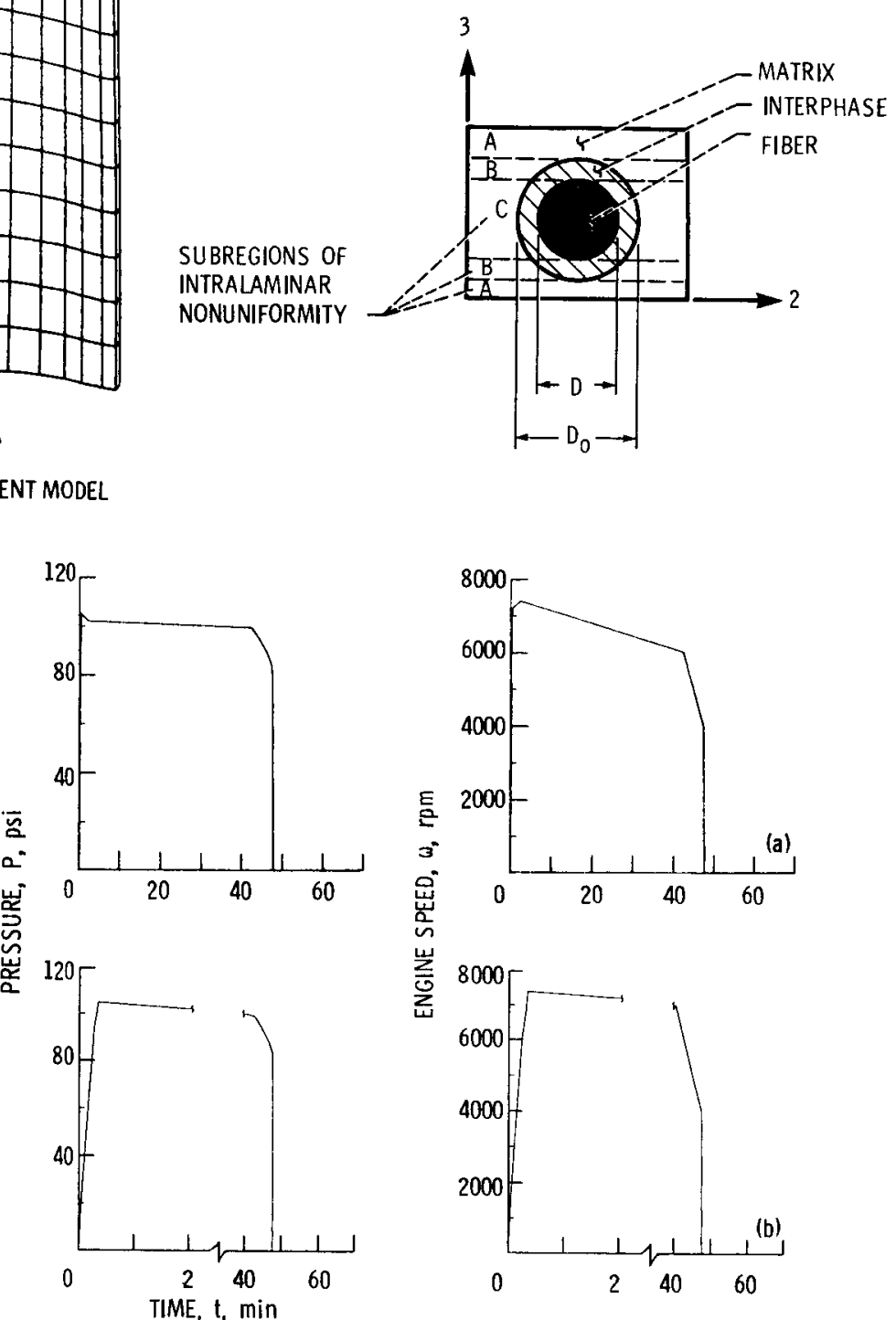

FIGURE 10. - METAL MATRIX COMPOSITE TURBINE BLADE, FINITE ELEMENT MODEL AND MISSION LOADS. 

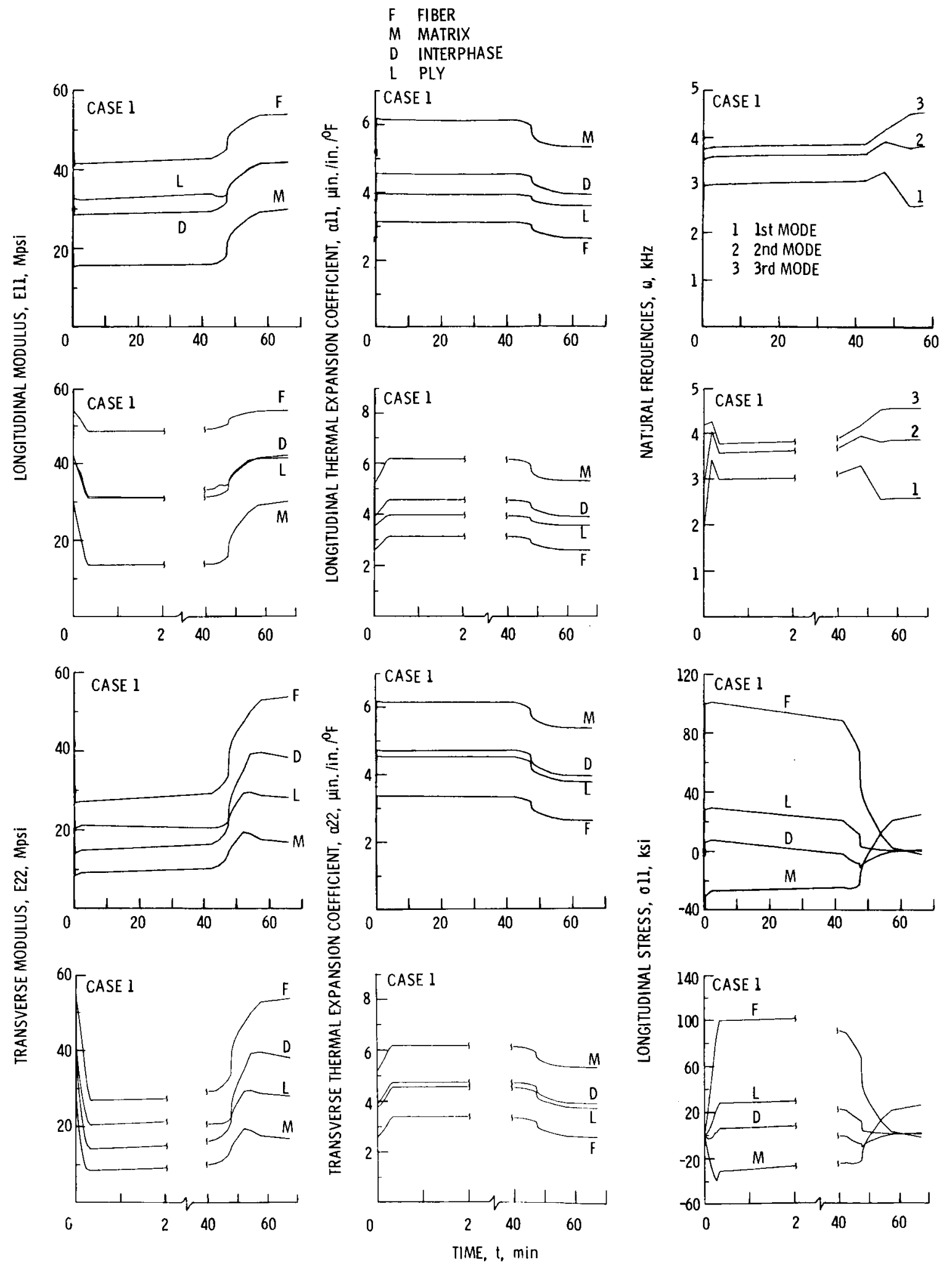

FIGURE 11. - NONLINEAR COSTRAN LOCALIGLOBAL METAL MATRIX COMPOSITE STRUCTURE BEHAVIOR. 


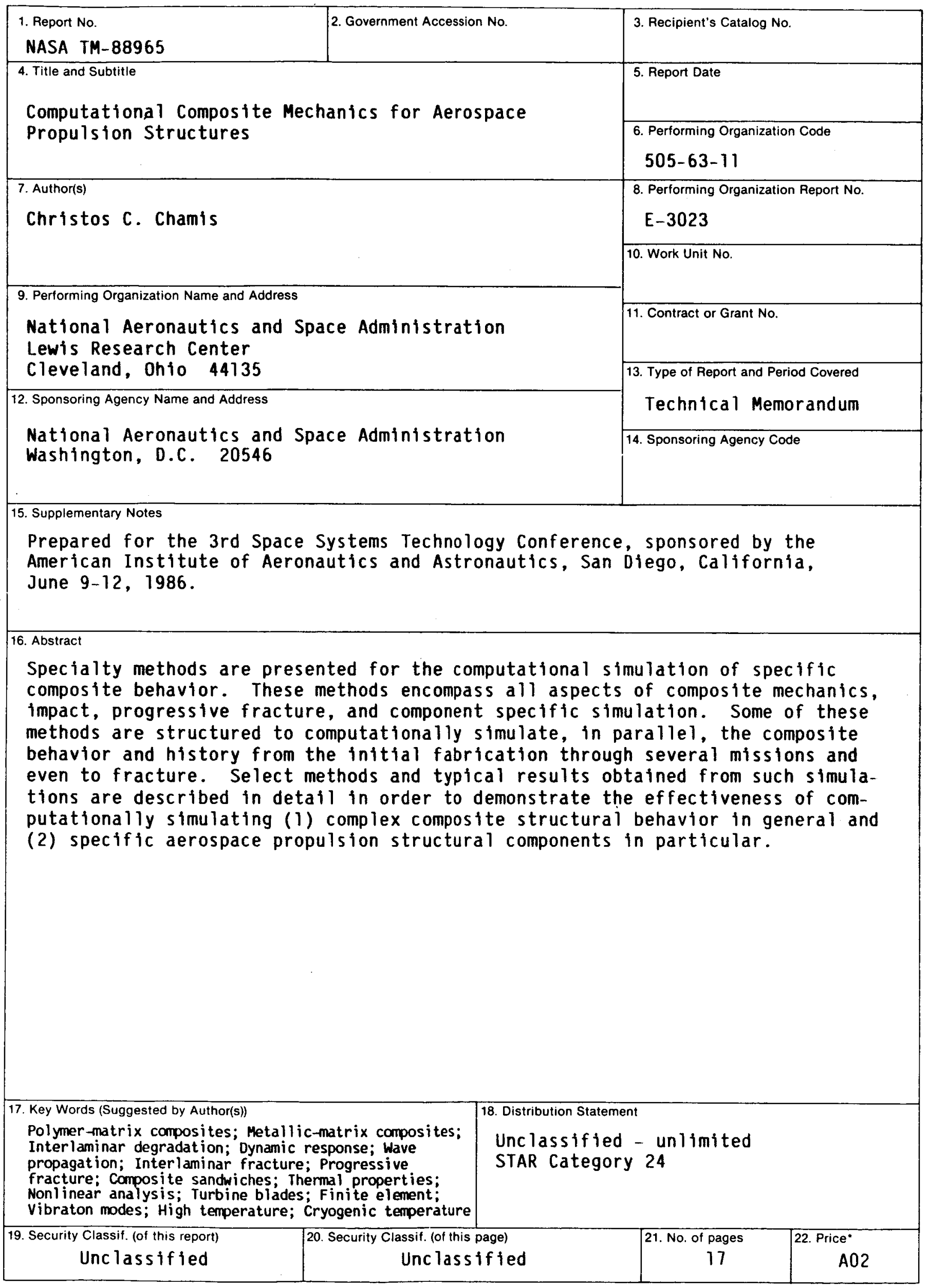

"For sale by the National Technical Information Service, Springfield, Virginia 22161 